\title{
O lugar da escrita na reflexão saussuriana sobre o objeto da Linguística
}

Giovane Fernandes Oliveira ${ }^{1}$

\section{Resumo}

O artigo ora apresentado visa a responder as seguintes questões: 1) Que noçoes de escrita podem ser derivadas da reflexão saussuriana sobre o objeto da Linguística? 2) Qual é o lugar assumido pela escrita na delimitação do objeto da ciência da língua no CLG? Para tanto, o estudo investiga as relações entre a escrita e a matéria da Linguística, a escrita e o objeto da Linguística e o lugar da escrita na zona fronteiriça entre as Linguísticas da língua e da fala e os elementos internos e externos à língua. A investigação levada a cabo permite derivar, da obra fundadora da Linguística moderna, diversas noções de escrita, cuja elaboração vai a par com a das noções de linguagem, lingua e fala, o que possibilita compreender a escrita como um contraponto necessário ao entendimento destas e, por conseguinte, do objeto da ciência da língua.

Palavras-chave: Linguagem. Lingua. Fala. Escrita. Objeto da Linguistica

\footnotetext{
${ }^{1}$ Doutorando e Mestre em Estudos da Linguagem pela linha de pesquisa "Análises Textuais, Discursivas e Enunciativas", do Programa de Pós-Graduação em Letras da Universidade Federal do Rio Grande do Sul (UFRGS).
} 


\section{Introdução}

A escrita tem sido o interrogante de estudos vinculados a diferentes áreas do conhecimento, como a Linguística, a Antropologia, a Educação, a Filosofia, a Psicanálise. Particularmente, temos observado tal fenômeno a partir das lentes dos estudos linguísticos da enunciação e dos estudos antropológicos do letramento (OLIVEIRA, 2016; OLIVEIRA, 2017a; OLIVEIRA, 2017b). Diferentemente desses estudos anteriores, contudo, este se propõe a investigar menos os aspectos discursivos e pedagógicos da escrita e mais o lugar que ela ocupa na reflexão saussuriana sobre o objeto da Linguística, o que implica examinar suas relações com algumas das noções basilares da rede conceitual tecida no Curso de Linguística Geral (doravante, CLG ou Curso), notadamente as noções de linguagem, lingua e fala.

Com efeito, é nas ideias de Ferdinand de Saussure, mais precisamente naquelas divulgadas pelo Curso, que buscamos o fundamento teórico para a reflexão esboçada neste artigo. Se é verdade que uma teoria da escrita supõe, necessariamente, uma teoria da linguagem (CHISS; PUECH, 1996), nada mais justo do que procurar na obra seminal da Linguística moderna a base para um estudo da escrita ${ }^{2}$. Além desse pressuposto geral, outras duas razões justificam a escolha do CLG como texto de referência do presente trabalho.

A primeira, de ordem epistemológica, deve-se ao fato de que nos aliamos aos estudiosos da herança saussuriana que não assumem a querela que opõe um pretenso "Saussure autêntico", o de manuscritos como os Escritos de Linguística Geral (doravante, ELG ou Escritos), a um suposto "pseudo-Saussure", aquele do Curso (BOUQUET, 2009). Tal querela, segundo Colombat, Fournier e Puech (2010), teve início com o surgimento de pesquisas filológicas em torno dos manuscritos saussurianos e de interpretações radicais que passaram a considerá-los as únicas fontes legítimas de pesquisa. Colocamo-nos, em contrapartida, ao lado de leitores franceses (GADET, 1990; NORMAND, 2009) e brasileiros (MILANO, 2015; FLORES, 2017) que reconhecem a importância histórica do

\footnotetext{
2 São exemplos de estudos que tratam do tema da escrita a partir do Curso ou passando por ele: o de Chiss e Puech (1983), que situa a obra de 1916 no debate mais amplo da questão da escrita na Linguística estrutural; o de Chiss e Puech (1996), que problematiza a representação da língua pela escrita no CLG; o de Testenoire (2016), que interroga o conceito de língua escrita nas teorizações linguísticas de Saussure e Bally; e o de Fenoglio (2017), que investiga a relação entre a língua e a escrita como um distanciamento teórico entre Saussure e Benveniste. Essa lista, obviamente, não se pretende exaustiva e busca apenas dar uma ideia de outros caminhos já percorridos por estudiosos interessados na relação Saussure-escrita.
} 
CLG enquanto discurso fundador e o seu potencial heurístico enquanto fonte inesgotável de inspiração.

Isso não significa que ignoramos a complexidade da gênese editorial do Curso, suas diferenças constitutivas com relação aos Escritos e a heterogeneidade do chamado corpus saussuriano. Significa, antes, que reconhecemos a necessidade de uma tomada ética de posição quanto a tais questões (FIORIN; FLORES; BARBISAN, 2013), a qual instaura um gesto de leitura e circunscreve os limites deste estudo. Falemos um pouco sobre esses três pontos: o CLG, os ELG e o corpus saussuriano.

O Curso de Linguística Geral, publicado em 1916, três anos após a morte de Saussure, não foi escrito por este, mas redigido e editado por dois colegas e discípulos seus, Charles Bally e Albert Sechehaye, com a colaboração de Albert Riedlinger, a partir de anotações do professor e, sobretudo, de notas de alunos que assistiram aos três cursos de Linguística Geral por ele ministrados, entre 1907 e 1911, na Universidade de Genebra. Conforme explicam os editores no prefácio da obra, trata-se de uma reconstituição, uma síntese, uma recriação das ideias saussurianas, empreendimento cuja ousadia e riscos eles não ignoravam, pois assumem a responsabilidade perante a crítica e o próprio Saussure, o qual, segundo os organizadores, talvez sequer tivesse autorizado tal publicação: “Saberá a crítica distinguir entre o mestre e seus intérpretes? Ficar-lhe-íamos gratos se dirigisse contra nós os golpes com que seria injusto oprimir uma memória que nos é querida" (BALLY; SECHEHAYE, 2012 [1916], p. 26).

A despeito da complexa questão autoral e das críticas filológicas em torno do estabelecimento do texto do CLG, não se pode negar hoje o papel do Curso e, consequentemente, o de Bally e Sechehaye como os principais responsáveis pelo efeito Saussure (NORMAND, 2009) na fundação da Linguística enquanto ciência e enquanto modelo de cientificidade para as demais ciências humanas e sociais no século XX. Ademais, os estudos exegéticos mais tarde realizados a partir das fontes manuscritas "deixaram visível que, no fundo (no núcleo duro), o que consta do CLG não é assim tão afastado do que pensava Saussure” (FARACO, 2016a, p. 20). O Curso segue sendo, portanto, uma fonte permanente de inspiração para reflexões sobre a linguagem humana e sua diversidade de fenômenos, dentre os quais se situa a escrita.

Os Escritos de Linguística Geral, publicados em 2002, com edição e organização de Simon Bouquet e Rudolf Engler, reúnem um conjunto de manuscritos de Saussure 
descobertos em 1996 na antiga residência de sua família e depositados na Biblioteca Pública e Universitária de Genebra. Como esclarecem os organizadores no prefácio do livro, além desses novos textos, integram o volume antigos manuscritos, já publicados na edição crítica de Engler em 1968. Tais escritos, apesar de seu caráter inacabado, lacunar e fragmentário, renovaram os estudos em torno da obra do linguista e confirmaram a potência de seu pensamento.

Sem negarmos a importância dos Escritos, restringiremos nossa reflexão sobre a escrita ao Curso, mais especificamente aos cinco primeiros capítulos da Introdução, nos quais a escrita comparece intensamente nas discussões que neles se desenvolvem em torno do objeto da Linguística. Assim, não abordaremos por ora outros capítulos da obra que problematizam a escrita, como o famoso Representação da língua pela escrita e os não menos conhecidos Natureza do signo linguístico e $O$ valor linguístico. Reservamos para o futuro, portanto, um estudo do tema a partir das demais partes do CLG e, quiçá, a partir também dos ELG e de outras fontes manuscritas saussurianas.

A respeito das fontes de pesquisa do legado saussuriano, Fiorin, Flores e Barbisan (2013) estabelecem uma distinção entre o que chamam de corpus saussuriano e corpus de pesquisa. O primeiro seria o conjunto de fontes documentais de diferentes naturezas disponíveis para pesquisa, o qual inclui o Curso, mas também textos publicados em vida por Saussure, manuscritos saussurianos publicados ou não, cartas pessoais e profissionais do linguista suíço, notas e cartas de alunos seus, edições críticas do CLG, dentre outros documentos. Já o segundo seria o corpus recortado, tendo em vista objetivos específicos de pesquisa, a partir desse conjunto heterogêneo de fontes, o que é, segundo os autores, uma condição indispensável para o estudo de Saussure na atualidade.

Dessa forma, apesar do fervoroso debate acerca da autoria do CLG, é essa a obra que, considerando o propósito do presente estudo, elegemos como corpus de nossa pesquisa, assim como é ao nome de Saussure que nos referimos, seguindo o padrão editorial adotado por outros estudiosos do linguista.

A segunda razão que justifica a escolha do CLG como nosso texto de referência é de ordem teórica e relaciona-se com a constatação da não pouco notável presença da escrita na Introdução da obra centenária, na qual ela parece figurar como um dos recursos aos quais recorre Saussure para circunscrever o objeto da ciência linguística. Dessa 
constatação, decorrem as seguintes perguntas de pesquisa, às quais procuraremos responder neste artigo:

1) Que noções de escrita podem ser derivadas da reflexão saussuriana sobre o objeto da Linguística?

2) Qual é o lugar assumido pela escrita na delimitação do objeto da ciência da língua no CLG?

Para tanto, realizaremos dois movimentos interpretativos no exame dos cinco capítulos selecionados como corpus deste estudo. O primeiro concerne à leitura das ocorrências do termo escrita e à análise das conceituações que o acompanham. O segundo movimento constitui-se no deslocamento, para o contexto deste artigo, de reflexões nas quais a escrita não comparece como termo de facto, mas pode ser apreendida como noção subjacente às exposições teóricas. Ambos os movimentos consistem em interpretações nossas acerca de noções presentes no CLG, mas também de noções derivadas de nossa leitura do Curso e de relações que estabelecemos com o objeto deste artigo, a escrita. Tratase, portanto, de uma leitura pessoal, sujeita a fragilidades e críticas como todo gesto interpretativo.

Em busca de respostas às questões norteadoras apresentadas, organizamos este texto em três seções, além desta introdução e da conclusão: na segunda seção, investigamos as relações entre a escrita e a matéria da Linguística; na terceira, as relações entre a escrita e o objeto da Linguística; na quarta, as relações entre a escrita e as Linguísticas da língua e da fala e os elementos internos e externos à língua.

\section{A escrita e a matéria da Linguística}

A Introdução do CLG caracteriza-se por apresentar os capítulos em que Saussure busca determinar a natureza do objeto da Linguística, o que ele compreende como uma operação elementar, sem a qual uma ciência não tem condições de definir para si um método.

No capítulo Visão geral da história da Linguística, o linguista aponta a Gramática Comparada como a última das três fases por que passou a ciência da língua até o início do século XX, sendo a Gramática Normativa e a Filologia as duas primeiras. Segundo o estudioso, apesar dos avanços que a escola comparatista trouxe aos estudos indo-europeus, 
ela "apega-se muito servilmente à língua escrita e esquece a língua falada" (SAUSSURE, 2012 [1916], p. 32, grifo nosso). O adjetivo grifado, nessa primeira menção à escrita no CLG, é ilustrativo da "posição desconfiada" que o Curso predominantemente assumirá com relação a ela ${ }^{3}$.

Essa atitude receosa em face da escrita justifica-se, na medida em que Saussure busca estabelecer as condições para a emergência de uma Linguística sincrônica, centrada no estudo da língua falada ${ }^{4}$ e, portanto, radicalmente distinta da Linguística - vigente em seu tempo, diacrônica, focada na investigação da evolução de uma ou mais línguas a partir de registros escritos.

Já no capítulo seguinte, Matéria e tarefa da Linguística; suas relações com as ciências conexas, a escrita é apresentada de modo mais positivo, como parte da matéria da Linguística, de forma que "o linguista deverá ter em conta os textos escritos, pois somente eles lhe farão conhecer os idiomas passados ou distantes" (SAUSSURE, 2012 [1916], p. 32). Quanto à presença da escrita nesse capítulo, fazemos três observações.

Primeira: a escrita é relacionada, aqui, à matéria da ciência linguística - "constituída inicialmente por todas as manifestações da linguagem humana” (SAUSSURE, 2012 [1916], p. 37) -, e não ao seu objeto, coisa bem diferente, conforme evidencia o capítulo posterior a esse.

Segunda observação: essa matéria inclui "todas as formas de expressão" (SAUSSURE, 2012 [1916], p. 37). Seria a escrita uma forma de expressão? Pensamos que sim, ou melhor, também. Retomaremos esse ponto adiante.

Terceira observação: a citação acima parece ir de encontro à crítica feita anteriormente à Gramática Comparada, porém tal crítica diz respeito, nesse capítulo, ao privilégio concedido pelos comparatistas à língua escrita em detrimento da língua falada, e não a uma suposta ilegitimidade da escrita enquanto matéria de estudo. Atestam isso duas outras passagens do capítulo:

\footnotetext{
3 Tal posição é explicitamente assumida no capítulo Representação da língua pela escrita, o qual, como já esclarecido, não integra o corpus desta pesquisa.

${ }^{4}$ No Brasil, testemunha a favor do lugar de destaque do fônico no CLG o estudo de Milano (2015), dentre outros realizados pela pesquisadora, sozinha e em coautoria.
} 
1) a primeira das tarefas elencadas para a Linguística, segundo a qual cabe a essa ciência fazer a descrição e a história de todas as línguas possíveis, o que só era possível à época - e, de certo modo, ainda hoje, considerando a necessidade de transcrição implicada em toda análise linguística - por meio de testemunhos escritos;

2) a primeira das "utilidades" assinaladas para a Linguística, de acordo com a qual "as questões linguísticas interessam a todos - historiadores, filólogos etc. - que tenham de manejar textos" (SAUSSURE, 2012 [1916], p. 38), trecho em que o termo textos, a julgar pelo aposto isolado entre travessões, parece se referir particularmente a textos escritos.

Nesse contexto, a escrita pode ser compreendida como uma forma de expressão dentre as muitas manifestações da linguagem humana que integram a matéria da Linguística, mas não o seu objeto, o qual "não é uma coisa inscrita no real dos fatos de linguagem, mas o princípio organizador de uma disciplina, um modo de ordenamento dos fatos" (GADET, 1990, p. 73) ${ }^{5}$. Essa, no entanto, não é a única noção de escrita que pode ser derivada da reflexão saussuriana sobre o objeto da ciência da língua, conforme a discussão realizada na seção seguinte.

\section{A escrita e o objeto da Linguística}

No capítulo Objeto da Linguística, Saussure defende que, na Linguística, o objeto não preexiste ao ponto de vista adotado para estudá-lo, mas é por este criado, o que o leva a definir o objeto da ciência linguística a partir de um ponto de vista que distingue as noções de linguagem, lingua e fala.

A linguagem é concebida como uma faculdade humana multiforme e heteróclita, simultaneamente física, fisiológica, psíquica, social e individual, heterogeneidade esta que a torna inclassificável numa única categoria humana.

Já a língua é definida como um produto da faculdade da linguagem, classificável no conjunto dos fatos humanos por ser social (porque exterior ao indivíduo, que o registra

\footnotetext{
5 No original: “[...] ce n’est pas une chose inscrite dans le réel des faits de langage, mais le principe organisateur d'une discipline, un mode d'ordonnancement des faits" (GADET, 1990, p. 73).
} 
passivamente como um instrumento imposto pela coletividade), autônomo (porque passível de ser estudado de modo independente, como um sistema gramatical que existe virtualmente nos cérebros dos membros de uma dada comunidade) e homogêneo (porque sistema de signos estável, com um funcionamento interno e regular).

A fala, por sua vez, é também tomada como um produto da faculdade da linguagem, mas, diferentemente da língua, não é um fato social, mas um ato individual de vontade e inteligência, que designa o uso particular que o falante faz do tesouro linguístico herdado socialmente.

Para Saussure, a linguagem e a fala não podem constituir o objeto da Linguística que inicialmente é necessário fundar. Enquanto a segunda é assistemática, acessória e acidental, escapando a qualquer tentativa de regularização, a primeira é tão heterogênea que pode ser reivindicada como objeto de estudo por domínios outros, como a Psicologia, a Antropologia, a Gramática Normativa, a Filologia, etc. Ao contrário, "a língua é um sistema que conhece somente sua ordem própria" (SAUSSURE, 2012 [1916], p. 55), cuja autonomia e homogeneidade a legitimam como objeto científico. Assim, seguindo o paradigma positivista de cientificidade dominante em sua época ${ }^{6}$, Saussure elege a língua como objeto da Linguística, um objeto sistêmico, imanente, autossuficiente.

Isso não significa que o mestre de Genebra ignore ou negue a interdependência entre linguagem, língua e fala, como ratifica o capítulo Linguística da língua e Linguística da fala. Neste, Saussure afirma que o estudo da linguagem comporta duas partes intimamente relacionadas, uma social e essencial (a língua), outra individual e secundária (a fala). Cada uma dessas partes constitui o objeto de uma Linguística própria, apontando caminhos que devem ser seguidos separadamente, ainda que estejam estreitamente vinculados, pois "a língua é necessária para que a fala seja inteligível e produza todos os seus efeitos; mas esta é necessária para que a língua se estabeleça", de modo que "Existe, pois, interdependência da língua e da fala; aquela é ao mesmo tempo o instrumento e o produto desta" (SAUSSURE, 2012 [1916], p. 51).

\footnotetext{
${ }^{6}$ Acerca da relação entre a Linguística saussuriana e a Filosofia positivista, Normand (2009) comenta que a questão sobre o objeto e o método não é uma invenção de Saussure, estando relacionada à reflexão positivista sobre as ciências: "Sob o efeito do positivismo filosófico, particularmente importante na França, a multiplicação das reflexões sobre 'a ciência', suas condições, seus métodos, seus resultados, convida os linguistas a esse domínio que deveria combinar a generalidade dos princípios e a síntese dos resultados" (NORMAND, 2009, p. 26).
} 
Esse vínculo estreito entre língua e fala fica evidente já no capítulo anterior, Objeto da Linguística, em que o linguista observa que, para situar o lugar da língua nos fatos de linguagem, deve-se colocar diante do ato individual de fala. Tal condição metodológica sinalizada por Saussure é esclarecida por Gadet (1990, p. 79), conforme a qual a língua não é diretamente observável, sendo a fala via obrigatória de acesso à língua. Para a autora, a oposição língua/fala contém uma oposição entre o concreto (fala) e o abstrato (língua), ainda que Saussure, inserido numa época de epistemologia kantiana, considere o termo abstrato pejorativo e procure dele desviar.

Desse modo, embora leituras canônicas do CLG tenham interpretado o par línguafala como uma dicotomia excludente, trata-se, antes, de uma dualidade constitutiva. São duas noções mutuamente pressupostas, cindidas por um corte epistemológico - oriundo do objetivo de instituir a Linguística como ciência -, no qual está implicada uma necessidade metodológica - a de recortar para essa ciência um objeto possível de ser estudado abstratamente, apesar de esse estudo abstrato não prescindir da materialidade concreta produzida pela fala.

A primeira ocorrência do termo escrita surge ainda na primeira seção do capítulo, intitulada A língua: sua definição, quando Saussure questiona o caráter natural atribuído à linguagem (falada) por muitos que utilizam como argumento a descoberta de Broca ${ }^{7}$ sobre a localização da faculdade de falar na terceira circunvolução frontal esquerda. Conforme o genebrino, "sabe-se que essa localização foi comprovada por tudo quanto se relaciona com a linguagem, inclusive a escrita" (SAUSSURE, 2012 [1916], p. 42). Além de surgir, no contexto dessa discussão, como um exemplo do caráter social e não natural da língua, a linguagem escrita é também relacionada por Saussure à linguagem falada ${ }^{8}$ em dois pontos:

1) as perturbações diversas da linguagem oral e da linguagem escrita estão ligadas de muitas formas;

2) na afasia ou na agrafia, o que está comprometido é mais o uso dos signos de uma linguagem regular do que propriamente a capacidade de pronunciar determinados sons ou de traçar determinados signos.

\footnotetext{
7 Segundo Tullio de Mauro, na nota $n^{\circ} 57$ de sua edição crítica do CLG, P. Broca foi um cirurgião francês que, em 1861, revigorou os estudos sobre as localizações cerebrais das funções mentais, ao mostrar que um doente havia perdido a faculdade de falar por causa de uma lesão na terceira circunvolução frontal esquerda. 8 Apesar das distinções estabelecidas entre linguagem e língua, o CLG utiliza os termos língua falada, língua escrita, linguagem falada e linguagem escrita como sinônimos na Introdução, de forma que empregamos tais termos conforme os capítulos em que ocorrem.
} 
Esses aspectos levam Saussure a concluir que, "acima desses diversos órgãos, existe uma faculdade mais geral, a que comanda os signos e que seria a faculdade linguística por excelência” (SAUSSURE, 2012 [1916], p. 42) .

Em outros termos, não está em jogo a natureza do signo - seja ela fônica, gráfica ou mesmo gestual, conforme o exemplo das línguas de sinais também mencionado por Saussure nesse capítulo -, uma vez que tal natureza é indiferente. Indiferente, pois "não é a linguagem falada $^{10}$ que é natural ao homem, mas a faculdade de constituir uma língua, vale dizer: um sistema de signos ${ }^{11}$ distintos correspondentes a ideias distintas", de maneira que "a faculdade - natural ou não - de articular palavras não se exerce senão com a ajuda de instrumento criado e fornecido pela coletividade" (SAUSSURE, 2012 [1916], p. 42, acréscimo e grifo nossos conforme a edição crítica de Tullio de Mauro). Essa faculdade é a linguagem e esse instrumento é a língua, conjunto de convenções adotadas por um corpo social para permitir o exercício da linguagem; e, sendo convencional, esse conjunto pode assumir qualquer natureza, isto é, qualquer materialidade (fônica, gráfica ou gestual).

Aqui, a escrita parece reivindicar o estatuto de sistema de signos linguístico, a exemplo da língua falada e da língua de sinais. Acerca disso, antecipando uma informação que retomaremos adiante, Arrivé (2010) menciona dois tipos de sistemas de signos a partir dos citados por Saussure. Os sistemas do primeiro tipo, exemplificados pela escrita e pelo alfabeto dos surdos-mudos, "derivam de um sistema de signos primeiro, o da língua, que eles têm por função manifestar em outra substância, visível (as letras e os gestos) em vez de ser audível (os sons da voz)". Já "Os três outros exemplos - mas sua lista [de Saussure]

\footnotetext{
${ }^{9}$ Embora o qualificativo linguística, em faculdade linguística, possa remeter em um primeiro momento à língua, a julgar pela teorização desenvolvida nessa parte do capítulo, pensamos não ser equivocado relacionar tal qualificativo à linguagem, de modo que essa faculdade mais geral que comanda os signos seria a faculdade da linguagem, e não a língua (que, aliás, não é uma faculdade, mas um sistema).

${ }^{10}$ Essa citação, na tradução brasileira do CLG, omite o adjetivo falada após linguagem, o que pode levar a crer que o Curso esteja afirmando, nessa passagem, que a faculdade da linguagem não é natural ao homem, quando, na verdade, afirma justamente o contrário, ao postular que não é a linguagem (língua) falada que é da ordem da natureza (visto o aparelho vocal ser secundário no problema da linguagem), mas a faculdade que possibilita a sua constituição enquanto sistema, isto é, a faculdade da linguagem. Tal afirmação sobre o caráter natural da faculdade da linguagem é, contudo, relativizada pelo aposto entre travessões na segunda passagem citada acima: “a faculdade - natural ou não - de articular palavras...". Mais um exemplo dos desafios hermenêuticos enfrentados pelo pesquisador da teoria saussuriana.

11 Nesse trecho, exemplo da flutuação terminológica existente no CLG, o termo signos parece assumir o sentido de significantes, enquanto o termo ideias parece assumir o sentido de significados, terminologia que só será fixada mais adiante no livro, no capítulo Natureza do signo linguístico, inserido na Primeira Parte do Curso. Na Introdução, além de signo e ideia, constam também, com as respectivas acepções, os termos imagem acústica e sentido.
} 
continua aberta por um insistente 'etc.' reduplicado - são os de sistemas de signos não linguísticos"12 (ARRIVÉ, 2010, p. 49).

Se aceitarmos a interpretação de Arrivé (2010), devemos considerar a existência de sistemas de signos linguísticos e não linguísticos. Nessa perspectiva, a escrita pode ser entendida como um sistema de signos linguístico, derivado da língua, a qual ele manifesta em outra substância. Veremos, todavia, que essa interpretação pode receber nuances.

Também na segunda seção do capítulo sobre o objeto da Linguística, intitulada Lugar da lingua nos fatos da linguagem, Saussure vale-se da escrita como um contraponto necessário ao entendimento da noção de língua. Após destacar características da língua já apresentadas acima, como o seu caráter social, autônomo e homogêneo, o genebrino aponta a sua natureza concreta como algo que facilita o seu estudo. Essa concretude reside no fato de que os signos linguísticos, ainda que psíquicos, não são abstrações ${ }^{13}$, pois consistem em associações entre sentidos e imagens acústicas sediadas no cérebro e firmadas pelo consenso social.

Outra evidência da natureza concreta da língua é, conforme Saussure, a tangibilidade dos signos linguísticos, que lhes é garantida pela possibilidade de serem fixados pela escrita em imagens convencionais. Isso seria impossível no que concerne ao ato de fala, cuja fonação implica uma diversidade de movimentos musculares dificilmente captáveis em seus pormenores. Já na língua, “não existe senão a imagem acústica, e esta pode traduzir-se numa imagem visual constante" (SAUSSURE, 2012 [1996], p. 47), reduzindo-se cada imagem acústica a um número restrito de fonemas, passíveis de representação por um número equivalente de signos na escrita. Tal possibilidade de fixação dos elementos da língua é o que faz com que "um dicionário e uma gramática possam representá-la fielmente, sendo ela o depósito das imagens acústicas e a escrita a forma tangível dessas imagens" (SAUSSURE, 2012 [1916], p. 47) ${ }^{14}$.

\footnotetext{
12 Os três outros exemplos de sistemas de signos mencionados por Saussure, como veremos a seguir, são os ritos simbólicos, as formas de polidez e os sinais militares.

13 Relembremos Gadet (1990) sobre a hesitação de Saussure em usar o termo abstrato, em função das interdições da cultura científica em que estava inscrito, o que não o impediu de ser considerado na atualidade "como um dos iniciadores do acesso à abstração no século XX”, embora o tenha conduzido a formulações tortuosas, como aquelas em que utiliza os termos psíquico e espiritual, "equivalentes aproximativos de um abstrato que não pode ser dito" (GADET, 1990, p. 79, grifos da autora, tradução nossa).

14 Essa suposta representação fiel da língua por instrumentos linguísticos como a gramática e o dicionário, a qual o capítulo Objeto da linguistica afirma ser possibilitada pela escrita, é questionada no capítulo Representação da lingua pela escrita, cujo objetivo é justamente pôr em causa a fidelidade da escrita em relação à língua: "[...] a palavra escrita se mistura tão intimamente com a palavra falada, da qual é a imagem, que acaba por usurpar-
} 
$\mathrm{Na}$ terceira e última seção do capítulo sobre o objeto da ciência linguística, cujo título é Lugar da língua nos fatos humanos. Semiologia, Saussure reafirma a tese de que a língua é uma instituição social, mas acrescenta que ela se distingue de todas as demais instituições da sociedade, políticas, jurídicas, etc., na medida em que é também um sistema semiológico: "A língua é um sistema de signos que exprimem ideias, e é comparável, por isso, à escrita, ao alfabeto dos surdos-mudos, aos ritos simbólicos, às formas de polidez, aos sinais militares etc. Ela é apenas o principal desses sistemas" (SAUSSURE, 2012 [1916], p. 47, grifo nosso).

Essa nova ordem de fatos coloca a língua e, por conseguinte, a Linguística sob o abrigo de uma ciência ainda por ser fundada, a Semiologia, cujo objeto será o estudo da vida dos signos no seio da vida social. Saussure vincula a Semiologia à Psicologia geral, mais especificamente à Psicologia social, ciências já consolidadas à época, de maneira que a vinculação da Linguística a elas reserva-lhe um lugar no cenário científico.

Para Saussure, é função do psicólogo definir o lugar preciso da ciência semiológica, cabendo ao linguista determinar o que faz da língua um sistema especial dentre os demais que compõem a Semiologia ${ }^{15}$. A esse respeito, questiona-se o suíço: por que a Linguística está subordinada à Semiologia se tem um objeto independente, o qual permite a ela aceder à condição de ciência autônoma? E ele próprio responde: o problema linguístico é, primeiramente, um problema semiológico, e a Linguística é um espaço privilegiado de desenvolvimento da Semiologia; contudo, é preciso estudar a língua em si, e não sob outros prismas, exteriores ao seu organismo.

Dentre os pontos de vista externos à língua, Saussure menciona a concepção superficial e dominante que a reduz a uma nomenclatura; a visão do psicólogo, que não ultrapassa a execução individual do signo, o qual é social por natureza; e a abordagem que o estuda socialmente, sublinhando os caracteres que assemelham a língua às demais instituições sociais, em detrimento dos caracteres específicos aos sistemas semiológicos em geral e ao sistema linguístico em particular. Sobre o primeiro ponto de vista, o linguista

lhe o papel principal; terminamos por dar maior importância à representação do signo vocal do que ao próprio signo. É como se acreditássemos que, para conhecer uma pessoa, melhor fosse contemplar-lhe a fotografia" (SAUSSURE, 2012 [1916], p. 58).

${ }^{15}$ Essa tarefa do linguista, apenas anunciada pelo mestre genebrino, parece ser aceita por um de seus mais notáveis herdeiros, Emile Benveniste, cujo artigo intitulado Semiologia da lingua busca explicitamente destacar os caracteres que singularizam a língua no conjunto dos sistemas semiológicos. Também o livro Últimas Aulas no College de France - 1968 e 1969, obra póstuma publicada a partir de notas manuscritas de Benveniste e de alunos que acompanharam seus últimos cursos no final da década de 1960, ilustra o interesse geral do linguista sírio pela Semiologia e o seu interesse particular pela relação desta com a língua e a escrita. 
declara que ele se distancia completamente da verdadeira natureza da língua. Sobre os dois outros, ressalta que "O signo escapa sempre, em certa medida, à vontade individual ou social, estando nisso o seu caráter essencial; é, porém, o que menos aparece à primeira vista” (SAUSSURE, 2012 [1916], p. 48).

De fato, o que define sobremaneira a concepção saussuriana de língua não é o traço social, que a situa como instituição da sociedade (visão compartilhada pelos contemporâneos de Saussure), mas o semiológico, que a postula como sistema de signos (este sim uma especificidade do pensamento do genebrino). Isso não significa que Saussure negue o caráter social da língua - ou mesmo que ela sirva para comunicar -, mas que ele não julga ser tal característica suficiente para fornecer ao linguista um ponto de vista e um método específicos.

A esse propósito, observa Normand (2009) que o suíço não considera o traço social o mais esclarecedor da natureza da língua, pois ela partilha esse traço com outras instituições da sociedade, de forma que é o traço semiológico que "permite definir um objeto próprio à linguística, uma ordem interna; história e sociedade são remetidas ao externo, que não se nega que possuam [sic] seus efeitos sobre a língua, mas cujo estudo é reservado a outras disciplinas e a um outro setor da linguística, aquele que é dito 'externo"” (NORMAND, 2009, p. 52, grifos da autora).

Quanto à relação entre o social e o semiológico, também Gadet (1990, p. 58-59) pontua que a originalidade da concepção saussuriana não está no reconhecimento de que a língua apresenta uma organização - ideia admitida desde a Antiguidade - nem que essa organização varia conforme cada língua - princípio subjacente à Linguística dos séculos XVIII e XIX e que Saussure apenas retoma e sistematiza. A novidade saussuriana é, para a autora, o a priori de que a língua constitui um sistema a partir dos materiais fônico e semântico.

Gadet (1990, p. 78) ressalta ainda que esses dois traços engendram duas redes de definição, uma sociológica (língua como instituição social) e outra semiológica (língua como sistema de signos), cuja compatibilidade é sustentada por dois pontos de vista em sentidos contrários: a) o sociológico resulta do semiológico, segundo o qual é por ser um sistema de valores que a língua resiste às inovações individuais e pode se estabelecer como uma instituição social; b) o semiológico resulta do sociológico, conforme o qual é por ter o arbitrário como 
característica principal e resultante de sua natureza social que a língua forma um sistema semiológico:

Com o sociológico, Saussure se situa em um terreno que ele compartilha com a grande maioria dos linguistas de sua época, enquanto o semiológico faz avançar uma proposição original, verdadeiro ato de nascença da linguística moderna. O semiológico permite a emergência do estudo abstrato da língua [...] (GADET, 1990, p. 78) ${ }^{16}$.

Além de possibilitar a gênese do estudo abstrato da língua como sistema formal, com uma ordem interna distinta da ordem externa da realidade social, o traço semiológico torna possível ao linguista a investigação da real natureza da língua a partir do que ela tem em comum com os demais sistemas de signos. Dentre tais sistemas, encontra-se a escrita, primeiro exemplo mencionado por Saussure. É a qualidade semiológica familiar a ambas que torna a língua comparável à escrita e a outros sistemas da mesma ordem. Se a língua é comparável à escrita, então língua e escrita são noções que não se recobrem, nem em termos sinonímicos (a língua é igual a escrita) nem em termos hiperonímicos (a língua subsume a escrita). De acordo com o linguista, semelhante comparação resulta na constatação de que "fatores linguísticos que aparecem, à primeira vista, como muito importantes (por exemplo: o funcionamento do aparelho vocal) devem ser considerados de secundária importância quando servirem somente para distinguir a língua dos outros sistemas" (SAUSSURE, 2012 [1916], p. 49).

Aqui, como em outras passagens, a despeito dos exemplos que expõe em suas demonstrações - os quais são, em sua maioria, extraídos da língua falada -, Saussure torna a restringir o protagonismo do fônico no estudo da língua, embora considere o fônico, o vocal como um fator linguístico. A partir dessa consideração, o gráfico, o escrito parece ser não um fator linguístico, mas um fator semiológico, o que viabiliza um estudo comparado da língua e da escrita. Compreende-se, assim, por que a tese de Arrivé (2010) sobre a escrita como sistema de signos linguístico pode ser, senão recusada - visto ter pertinência o argumento do autor sobre o sistema escrito ser linguístico por reproduzir a língua em outra materialidade -, ao menos confrontada com outras teses, como a da escrita como sistema semiológico não linguístico, porque comparável ao (e, portanto, distinto do) sistema semiológico linguístico.

\footnotetext{
${ }^{16}$ No original: “Avec le sociologique, Saussure se situe sur un terrain qu'il partage avec la plus grande partie des linguistes de son époque, alors que le sémiologique avance une proposition originale, véritable acte de naissance de la linguiste moderne. Le sémiologique permet l'émergence de l'étude abstraite de la langue [...]" (GADET, 1990, p. 78).
} 
Nos dois capítulos seguintes da Introdução do CLG, Linguística da língua e Linguística da fala e Elementos internos e elementos externos da língua, não há ocorrências do termo escrita. Entretanto, as reflexões sobre linguagem, língua e fala neles contidas nos autorizam a operar deslocamentos para pensar a escrita no quadro da teorização sobre o objeto da Linguística, mais especificamente como ela se situa no limiar entre as Linguísticas da língua e da fala e os elementos internos e externos à língua. É isso o que buscamos levar a termo a seguir.

\section{A escrita numa zona fronteiriça}

Enquanto no capítulo Objeto da Linguistica o funcionamento do aparelho vocal é apresentado como um fator linguístico de menor importância, no capítulo Linguística da língua e Linguística da fala, essa ideia parece ser radicalizada, pois os órgãos vocais são descritos como sendo "tão exteriores à língua como os aparelhos elétricos que servem para transcrever o alfabeto Morse são estranhos a esse alfabeto” (SAUSSURE, 2012 [1916], p. 51). A minimização do papel dos órgãos vocais deve-se ao posicionamento de Saussure de que a língua existe independentemente da produção dos sons na fala, isto é, da fonação, e mesmo as transformações fonéticas que repercutem na língua não alcançam mais do que $a$ substância material das palavras. Se essas alterações sonoras "atacam a língua enquanto sistema de signos, fazem-no apenas indiretamente, pela mudança de interpretação que daí resulta; ora, esse fenômeno nada tem de fonético” (SAUSSURE, 2012 [1916], p. 51).

Se nada tem de fonético, tal fenômeno de mutação pode ser pensado também à luz das transformações de grafia resultantes de acordos ortográficos ${ }^{17}$, as quais incidem tãosomente sobre a substância material das palavras escritas, sem comprometer $\mathrm{O}$ funcionamento interno da escrita como sistema de signos. A título de exemplo, poderíamos citar a queda do acento diferencial em alguns pares lexicais do português, após o Acordo

\footnotetext{
${ }^{17}$ Faraco (2016b) distingue as noções de reforma ortográfica e acordo ortográfico: para o autor, uma reforma altera substancialmente as bases do sistema gráfico, enquanto um acordo busca apenas fazer alguns ajustes a fim de unificar ortografias. De acordo com o linguista, a ortografia da língua portuguesa sofreu apenas uma reforma, em 1911, quando foi adotada a ortografia simplificada e substituiu-se a memória etimológica pela transparência fonológica como principal critério estruturador do sistema gráfico. Uma vez aceita a distinção proposta por Faraco (2016b), podemos concluir que, diferentemente de um acordo ortográfico - que não faz senão modificações de superfície -, uma reforma ortográfica transforma os fundamentos da escrita enquanto sistema de signos, modificando seu funcionamento semiológico. Este seria o caso da reforma radical à qual foi submetida, nos anos 1920, a escrita do turco, que mudou o próprio alfabeto da língua, substituindo o alfabeto árabe pelo latino.
} 
Ortográfico de 1990, como para (forma verbal, antes pára) e para (preposição), ou ainda, pelo (substantivo, antes pêlo) e pelo (preposição). Tal mudança não afetou senão a materialidade das palavras gráficas, convertendo-as em homônimos ditos perfeitos, porque pronunciados e escritos da mesma maneira; em nada modificou, porém, a escrita enquanto sistema semiológico, resultando apenas em alguma mudança de interpretação dos signos gráficos.

E Saussure (2012 [1916], p. 51) acrescenta: “[...] o que dizemos da fonação será verdadeiro no tocante a todas as outras partes da fala. A atividade de quem fala deve ser estudada num conjunto de disciplinas que somente por sua relação com a língua têm lugar na Linguística”. Quais outras partes seriam essas? A escrita seria uma delas?

Para Normand (2009), sim: "Que os locutores, ao trocarem suas falas (e fala designa em Saussure tanto o escrito quanto oral), possam se comunicar os pensamentos é um objeto de espanto de que os filósofos tomaram consciência desde sempre sem resolver o mistério dessa função de representação" (NORMAND, 2009, p. 55, grifo e parênteses da autora). Embora responda afirmativamente a tal pergunta, a autora não nos proporciona maiores explicações. Sem desejarmos refutar de todo sua tese, gostaríamos, ao menos, de relativizá-la.

A escrita pode, sim, ser assimilada à parole saussuriana, enquanto manifestação individual e momentânea da langue. Mas isso só é verdade para a escrita entendida como ato de uso da língua em sua realização gráfica, em contraste com a oralidade compreendida como emprego do sistema linguístico em sua materialização fônica. A noção de escrita não abarca, entretanto, apenas essa acepção instrumental - que parece dialogar com a noção de forma de expressão, presente no capítulo Matéria e tarefa da Linguística -, comportando ainda um sentindo outro quando o que está em jogo é o seu caráter sistêmico.

Este requer que ultrapassemos o domínio da fala como mise en ouvre da língua para pensar a escrita no domínio da Semiologia. Nesse domínio, ela deve ser concebida como um sistema organizado, que, como a língua, apresenta unidades significantes em relação, regidas pelo princípio do arbitrário do signo, o qual faz da escrita também uma instituição social, produto da cultura humana.

No capítulo Elementos internos e elementos externos da língua, a escrita não comparece enquanto termo, mas podemos percebê-la enquanto noção subjacente a algumas relações estabelecidas por Saussure entre a língua e elementos exteriores a ela. Dentre esses 
elementos, dos quais se ocupa a "Linguística externa", o linguista menciona as relações entre a língua e os costumes de uma raça/civilização/nação, as relações entre a língua e eventos histórico-políticos como conquistas e colonizações, as relações entre a língua e instituições sociais como a Igreja e a escola, as relações entre a língua e questões geográficas como o fracionamento dialetal.

Tudo isso diz respeito, segundo Saussure, ao estudo da linguagem, à Linguística externa, e não ao estudo da língua, à Linguística interna, pois tais fenômenos diversos, ainda que sejam “coisas importantes” (SAUSSURE, 2012 [1916], p. 53), não afetam o organismo interno do idioma. Trata-se de duas Linguísticas distintas, com dois diferentes pontos de vista, cuja separação se nos impõe, de modo que "cada um deles cria um método distinto" (SAUSSURE, 2012 [1916], p. 55). A esse propósito, é apropriado o comentário de Flores (2016), em estudo no qual busca produzir uma leitura do antropológico no CLG:

Não se pode dizer com tranquilidade que Saussure ignore os aspectos socioculturais, nem as forças de mudança, de variação e de conservação da língua. Ele apenas os exclui da linguística da língua, legando-os ao domínio da "linguística externa". Trata-se de uma questão de ponto de vista: se o ponto de vista é o do sistema da lingua, olha-se o sistema e, para isso, temse a "linguistica interna"; se, ao contrário, o ponto de vista é externo ao sistema, temse a "inguística externa" (FLORES, 2016, p. 85, grifo nosso).

Seria, então, a escrita uma matéria da Linguística externa? Cremos que sim. Dois pontos mencionados por Saussure, nesse capítulo, podem nos ajudar a elaborar uma reflexão nesse sentido: a) as línguas especiais surgidas em sociedades desenvolvidas e b) a língua literária fomentada pela religião e pela educação.

Quanto ao ponto (a), o linguista de Genebra afirma que "Um grau avançado de civilização favorece o desenvolvimento de certas línguas especiais (língua jurídica, terminologia científica, etc.)" (SAUSSURE, 2012 [1916], p. 54). Ainda que essas línguas especiais não se circunscrevam à escrita, não se pode negar a influência que esta exerce naquelas. Ilustram isso os usos particulares que certos grupos sociais fazem da língua, particularidades que incidem tanto na escrita quanto na oralidade letrada, como é o caso dos modos de dizer característicos de advogados, cientistas, jornalistas, etc. Esses grupos partilham a mesma língua, mas estabeleceram historicamente um léxico específico e formas também específicas de dispor os itens lexicais nas cadeias falada e escrita. Tal diversificação dos usos da língua deve-se, sem dúvida alguma, à expansão dos usos da escrita na modernidade, a partir da consolidação da universidade, da invenção da imprensa, do 
surgimento da indústria e de outros avanços científicos e tecnológicos que acompanharam a instauração da escrita em sociedades cosmopolitas cada vez mais complexas.

Quanto ao ponto (b), diretamente ligado ao primeiro, Saussure assinala que o desenvolvimento literário de uma língua relaciona-se estreitamente com instituições como a Igreja e a escola, sendo inseparável também da história política. Além disso, "A língua literária ultrapassa, em todas as partes, os limites que lhe parece traçar a literatura: recordese a influência dos salões, da corte, das academias" (SAUSSURE, 2012 [1916], p. 54). Essa transposição pelo fenômeno literário das fronteiras que lhe são impostas pela própria literatura remete ainda à "questão do conflito que se estabelece entre ela e os dialetos locais", de maneira que "o linguista deve também examinar as relações recíprocas entre a língua literária e a língua corrente; pois toda língua literária, produto da cultura, acaba por separar sua esfera de existência da esfera natural, a da língua falada" (SAUSSURE, 2012 [1916], p. 54). Sobre essa última citação, fazemos algumas ressalvas.

Primeira: língua literária parece assumir, aqui, o sentido de língua escrita - e, considerando a menção à ultrapassagem dos limites do literário e a referência aos salões, à corte, às academias, esse termo parece assumir também o sentido de língua falada que incorpora traços do escrito, em situações mais formais de interlocução -, enquanto língua corrente parece estar em relação sinonímica com língua falada e dialetos locais.

Segunda ressalva: tal entendimento de língua literária como língua escrita talvez seja ratificado pela expressão "Isso nos leva a..." (SAUSSURE, 2012 [1916], p. 54), que articula o parágrafo anterior (sobre as línguas especiais) ao parágrafo seguinte (sobre a língua literária), o que parece autorizar a conclusão de que a língua literária seja uma espécie de língua especial ou - o que é mais provável - a de que as línguas especiais sejam espécies de línguas literárias, já que a expressão "toda língua literária” faz supor que não há apenas uma língua literária, mas várias.

Terceira ressalva: essas línguas literárias (ou especiais) têm existência na esfera cultural, diferentemente da língua falada (ou corrente), cuja existência está atrelada à esfera natural, sintagma em que o termo natural parece corresponder a espontâneo, e não propriamente à natureza.

Quarta ressalva (na verdade, uma provocação): a incumbência destinada ao linguista - que engaja sua pesquisa na Linguística externa - de investigar as relações recíprocas entre a 
língua literária e a língua corrente, a questão do conflito entre ela e os dialetos locais estaria antecipando o debate que, décadas mais tarde, a Sociolinguística consagraria acerca da variação linguística e da relação conflituosa entre norma e uso, entre língua padrão enquanto variedade de prestígio e dialetos (regionais, sociais, etc.) enquanto variedades estigmatizadas?

Até aqui, analisamos as relações entre linguagem, língua, fala e escrita. Essa análise nos permitiu melhor compreender como tais noções se imbricam na definição do ponto de vista teórico que cria, para a Linguística, um objeto próprio (a língua como sistema de signos) e the possibilita reivindicar o estatuto de disciplina científica. Permitiu-nos compreender ainda o lugar, ou melhor, os lugares que a escrita assume nessa constituição disciplinar. Na seção final que segue, retomaremos, a título de sistematização, esses lugares.

\section{Conclusão}

Neste estudo, procuramos esmiuçar as relações entre linguagem, língua, fala e escrita que têm lugar nos primeiros cinco capítulos da Introdução do Curso de Linguística Geral. Submeter tais relações ao escrutínio exigiu dois movimentos interpretativos: a) o movimento de leitura das ocorrências do termo escrita e de análise das conceituações que o acompanham; b) o movimento de deslocamento, para o contexto deste artigo, de reflexões nas quais a escrita não comparece como termo de facto, mas pode ser apreendida como noção subjacente às exposições teóricas. Esse duplo movimento de interpretação teve por objetivo produzir uma reflexão que permitisse responder às duas perguntas de pesquisa formuladas na seção introdutória deste texto, a saber:

1) Que noções de escrita podem ser derivadas da reflexão saussuriana sobre o objeto da Linguística?

2) Qual é o lugar assumido pela escrita na delimitação do objeto da ciência da língua no CLG?

Para responder à primeira questão, recorremos à síntese abaixo, que sistematiza os pontos-chave da discussão realizada nas seções anteriores:

i. a escrita faz parte da matéria da Linguística, sendo uma das múltiplas manifestações da linguagem humana - sob esse ponto de vista, a escrita pode ser concebida como uma forma de expressão; 
ii. a linguagem é uma faculdade humana multifacetada e heterogênea que comporta uma parte social (a língua) e uma parte individual (a fala);

iii. a língua é um sistema de signos que não conhece senão sua ordem própria, independente da ordem da realidade, ainda que esteja nela inscrita enquanto instituição social;

iv. a fala é um ato individual de uso do sistema linguístico que submete a homogeneidade deste à heterogeneidade característica da linguagem;

v. a língua e a fala são fenômenos empiricamente indissociáveis, mas constituem objetos teórica e metodologicamente distintos, cada qual pertencendo a uma Linguística;

vi. a faculdade da linguagem é exercida por meio da língua enquanto sistema de signos que, por ter uma natureza convencional, pode assumir distintas materialidades (fônica, gráfica ou gestual), conforme o corpo social que o adota - sob esse ponto de vista, a escrita pode ser concebida como um sistema de signos linguístico;

vii. a Linguística interna, que estuda a língua como sistema de signos, insere-se numa ciência maior, a Semiologia, cujo objeto é o conjunto dos sistemas semiológicos em sua circulação social, sendo a escrita um desses sistemas e, por isso, comparável à língua, embora dela distinta - sob esse ponto de vista, a escrita pode ser concebida como um sistema semiológico não linguístico;

viii. a Linguística externa, que estuda "Todos os outros elementos da linguagem, que constituem a fala" (SAUSSURE, 2012 [1916], p. 50), inclui a escrita como uma forma de fala - sob esse ponto de vista, a escrita pode ser concebida como um ato de uso da lingua em sua realização gráfica;

ix. a escrita enquanto sistema semiológico partilha com a língua o estatuto de instituição social - sob esse ponto de vista, a escrita pode ser concebida como um produto da cultura bumana;

x. a escrita enquanto parte da Linguística externa relaciona-se a grupos sociais que fazem dela usos particulares - sob esse ponto de vista, a escrita pode ser concebida como um conjunto de linguas especiais, vinculadas a distintas funçoes nas sociedades modernas;

xi. a escrita enquanto parte da Linguística externa firma estreitas relações com a oralidade, sejam relações de semelhança, quando suas fronteiras são 
questionadas em situações mais formais de interlocução ${ }^{18}$, sejam relações de diferença, quando seus limites são demarcados a partir das suas distintas esferas de realização - sob esse ponto de vista, a escrita pode ser concebida como um conjunto de línguas literárias, as quais têm na esfera cultural a sua instância de concretiz̧aşão.

Quanto ao segundo interrogante acima, a escrita relaciona-se com as noções de linguagem, língua e fala como um contraponto necessário, no CLG, ao entendimento destas na delimitação do objeto da Linguística saussuriana. Em outras palavras, a exemplo dos elementos do sistema linguístico, tal objeto só adquire sua realidade teórica nas relações de diferença e de oposição entre as três referidas noções e entre elas e a escrita, a qual assume distintos lugares nessas relações fundantes da ciência linguística. Esses distintos lugares correspondem a diferentes pontos de vista sobre a escrita, cada um dos quais permite entrever um método próprio de estudo dela.

A escrita pode ser, portanto, associada tanto à matéria (o conjunto geral dos fenômenos da linguagem e da fala) quanto ao objeto da Linguística (o terreno específico da língua). Nessa perspectiva, entendida como o estabelecimento de um princípio organizador de uma disciplina, a posição que circunscreve o objeto da ciência linguística "preserva o direito à existência de outros pontos de vista sobre a linguagem, não linguísticos” (GADET, 1990, p. 73) ${ }^{19}$. De igual maneira, a exclusão da escrita do objeto da Linguística interna - como indica a maioria das concepções de escrita acima delineadas - resguarda sua legitimidade como matéria de estudo da Linguística externa.

Este trabalho teve como corpus alguns capítulos da Introdução do CLG, compreendendo-o - no conjunto das fontes de pesquisa saussurianas - como "um texto de ideias, de reflexão absolutamente original sobre a linguagem, a especificidade do objeto língua, as armadilhas da evidência e da trivialidade nas ciências humanas" (NORMAND, 2009, p. 18-19). Mesmo na Introdução do Curso, no entanto, uma segunda clivagem fez-se necessária: abordamos os cinco primeiros capítulos, enfocando as reflexões que nele

\footnotetext{
${ }^{18} \mathrm{Na}$ atualidade, o questionamento dessas fronteiras entre o escrito e o oral dá-se também - embora já não se trate mais de casos relacionados ao que Saussure parece denominar línguas literárias - em contextos menos formais de interação, como redes sociais virtuais e aplicativos eletrônicos de comunicação, nos quais a língua escrita se reveste de características da língua falada espontânea.

${ }^{19}$ No original: "Cette position préserve le droit à l'existence d'autres points de vue sur le langage, non linguistiques” (GADET, 1990, p. 73).
} 
tomam corpo acerca do objeto da Linguística, de maneira que outros capítulos da obra secular permanecem em suspenso, à espera de uma leitura mais atenta.

É o caso do capítulo VI da Introdução, Representação da língua pela escrita, o qual, ao tematizar as relações entre o fônico e o gráfico, apresenta-se como imprescindível para uma reflexão mais aprofundada sobre a escrita a partir do CLG. É também o caso do capítulo I da Primeira Parte, Natureza do signo linguístico, e do capítulo IV da Segunda Parte, O valor linguístico: o primeiro menciona a escrita ao tratar da linearidade do significante, princípio do qual depende todo o mecanismo da língua; já o segundo pede luzes à escrita ao explorar o valor linguístico em seu aspecto material. Em ambos os capítulos, a escrita emerge novamente, na teorização saussuriana, como "termo de comparação para esclarecer toda a questão" (SAUSSURE, 2012 [1916], p. 166). A incursão nesses e em outros capítulos reservamos a estudos posteriores a respeito da relação entre a escrita e tal compêndio fascinante que é o marco da Linguística moderna.

Tomando o Curso como fonte inspiradora, a despeito de todas as críticas que lhe são dirigidas, pensamos realizar um estudo que se inscreve no que Flores (2017, p. 31) nomeia de pesquisa prospectiva em torno da obra de Saussure, um tipo de pesquisa que, sem deixar de retornar aos fundamentos do pensamento saussuriano, busca, a partir destes, "avaliar a potencialidade que ele tem de dar horizontes ao campo do qual ele mesmo se origina".

Nesse sentido, acompanhamos Fiorin, Flores e Barbisan (2013, p. 10) e consideramos que "Saussure não é um autor embolorado, mas que ele ainda tem coisas a nos ensinar". Defender a atualidade das ideias saussurianas significa recusar o estatuto de letra morta que lhes é conferido (SILVEIRA, 2003), significa considerá-las como algo a mais do que um momento datado da história das ideias linguísticas, pois "o texto saussuriano ainda aponta caminhos, abre sendas e veredas, permite descortinar horizontes" (FIORIN; FLORES; BARBISAN, 2013, p. 10).

Dentre esses horizontes, destaca-se a escrita, aqui vista como um fenômeno de linguagem que muito tem a dizer à Linguística e ao linguista. Basta para isso que ele não lhe feche os ouvidos, ou melhor, os olhos. 


\section{Agradecimentos}

Este artigo, como todo texto, é produto de interlocuções que muito o qualificaram. Agradeço a leitura atenta e generosa dos colegas e amigos Carolina Knack e Lauro Gomes. Agradeço, em especial, aos preciosos apontamentos feitos pelas Profas. Dras. Luiza Ely Milano e Carmem Luci da Costa Silva. As faltas que persistirem são de minha inteira responsabilidade.

\section{Referências}

ARRIVÉ, Michel. Em busca de Ferdinand de Saussure. São Paulo: Parábola Editorial, 2010.

BALLY, Charles; SECHEHAYE. Prefácio à primeira edição. In: SAUSSURE, Ferdinand de. Curso de Linguística Geral. 28 ed. São Paulo: Cultrix, 2012 [1916], p. 23-26.

BOUQUET, Simon. De um pseudo-Saussure aos textos saussurianos originais. Letras $\boldsymbol{\&}$ Letras, Uberlância, v. 25, nº 1, p. 161-175, 2009.

CHISS, Jean-Louis; PUECH, Christian. La linguistique et la question de l'écriture: enjeux et débats autour de Saussure et les problématiques structurales. Langue française, $n^{\circ} 59$, p. 5-24, 1983.

O Cours de linguistique générale e a representação da língua pela escrita. In: CATACH, Nina (Org.). Para uma teoria da língua escrita. São Paulo: Ática, 1996, p. 43 52.

COLOMBAT, Bernard; FOURNIER, Jean-Marie; PUECH, Christian. Quelles ont été historiquement les réceptions du Cours de linguistique générale de Saussure? In: COLOMBAT, Bernard; FOURNIER, Jean-Marie; PUECH, Christian. Histoire des idées sur le langage et les langues. Paris: Klincksieck, 2010.

FARACO, Carlos Alberto. Apresentação. In: FARACO, Carlos Alberto (Org.). O efeito Saussure - cem anos do Curso de linguística geral. São Paulo: Parábola Editorial, 2016a, p. $7-24$.

FARACO, Carlos Alberto. Linguagem escrita e alfabetização. São Paulo: Contexto, 2016b.

FENOGLIO, Irène. "A língua e a escrita": um distanciamento teórico entre Saussure e Benveniste. Revista do GELNE, Natal, v. 19, no especial, p. 273-298, 2017.

FIORIN, José Luiz; FLORES, Valdir do Nascimento; BARBISAN, Leci Borges. Por que ainda ler Saussure? In: FIORIN, José Luiz; FLORES, Valdir do Nascimento; BARBISAN, Leci Borges (Org.). Saussure: a invenção da linguística. São Paulo: Contexto, 2013, p. 7-20. 
FLORES, Valdir do Nascimento. Notas para uma leitura do antropológico no Curso de linguística geral. In: FARACO, Carlos Alberto (Org.). O efeito Saussure - cem anos do Curso de linguística geral. São Paulo: Parábola Editorial, 2016, p. 73-90.

Saussure e Benveniste no Brasil: quatro aulas na École Normale Supérieure. São Paulo: Parábola Editorial, 2017.

GADET, Françoise. Saussure. Une Science de la langue. 2 ed. Paris: PUF, 1990.

MILANO, Luiza Ely. Fonético e fonológico em Saussure: o lugar do fônico no Curso de Linguística Geral. Eutomia, Recife, v. 16, nº 1, p. 245-258, 2015.

NORMAND, Claudine. Saussure. São Paulo: Estação Liberdade, 2009.

OLIVEIRA, Giovane Fernandes. Do homem na língua ao sujeito na escrita: bases para um diálogo entre Letramento e Enunciação. Trabalho de Conclusão de Curso (Licenciatura em Letras). Porto Alegre: Universidade Federal do Rio Grande do Sul, 2016.

- Os estudos dos letramentos acadêmicos no Brasil: influências, origens e perspectivas. Revista DisSol - Discurso, Sociedade e Linguagem, Pouso Alegre, ano IV, no 5, jan./jun. 2017a.

Letramento e enunciação: bases para um diálogo. Domínios de Lingu@gem, Uberlândia, v. 11, p. 1205-1245, 2017b.

SAUSSURE, Ferdinand de. Curso de Linguística Geral. 28 ed. São Paulo: Cultrix, 2012 [1916].

SILVEIRA, Eliane. As marcas do movimento de Saussure na fundação da lingüística. Tese (Doutorado em Linguística). Campinas: Universidade Estadual de Campinas, 2003.

TESTENOIRE, Pierre-Yves. Sur la conceptualisation de la «langue écrite» dans les théorisations linguistiques du début du XXe siècle. Dossiers d'HEL: écriture(s) et représentations du langage et des langues, n 9, p. 34-46, 2016. 


\section{Abstract}

The present article aims to answer the following questions: 1) What notions of writing can be derived from the Saussurean reflection on the object of Linguistics? 2) What is the place that writing takes in the delimitation of the object of the science of language in the Course of General Linguistics? Therefore, the study investigates the relations between writing and the matter of Linguistics, the writing and the object of Linguistics and the place of writing in the frontier zone between the Linguistics of language and the Linguistics of speech and the elements that are both internal and external to language. The undertaken research allows us to derive, from the founding work of modern Linguistics, several notions of writing, whose elaboration goes hand in hand with the notions of language, langue and parole, which therefore enable us to comprehend writing as a necessary counterpoint to the understanding of these notions and, consequently, of the object of the science of language.

Keywords: Langage. Langue. Parole. Writing. Object of Linguistics

Recebido em: 30/04/2018.

Aceito em: 01/07/2018. 